\title{
CREATION OF UNISCOPE: A MODEL FOR REWARDING ALL FORMS OF SCHOLARSHIP
}

\author{
Elise A. Gurgevich \\ Outreach and Cooperative Extension, The Pennsylvania State University \\ University Park, PA 16802 \\ Email: EliseG@psu.edu \\ Drew Hyman \\ College of Agricultural Sciences, The Pennsylvania State University \\ University Park, PA 16802 \\ Email:dwh@psu.edu \\ Theodore R. Alter \\ Outreach and Cooperative Extension, The Pennsylvania State University \\ University Park, PA 16802 \\ Email: talter@psu.edu
}

\begin{abstract}
On March 24, 1998, a small group of faculty and administrators at the Pennsylvania State University (PSU) formed a learning community to engage in a deliberative dialogue about recognizing and documenting outreach scholarship in the University. We chose UniSCOPE, University Scholarship and Criteria for Outreach and Performance Evaluation, as a title to encapsulate our mission. Our goal was to consider the meaning of scholarship in the contemporary university and to consider the role of outreach therein. We did this in the context of the Penn State promotion and tenure system to gain a better understanding of its effect on scholarship. We quickly learned that outreach scholarship cannot be examined in isolation, and we broadened our deliberations to consider the full range of scholarship. This report articulates a multidimensional model of scholarship in general, of which outreach scholarship is a key component and presents our recommendations for action.
\end{abstract}

\section{KEYWORDS}

Scholarship, Promotion, Tenure, Outreach, Faculty Satisfaction

\section{INTRODUCTION}

To satisfy the growing demands of living in an increasingly complex global society, the public expects more from higher education now than ever before. The Information Age with its rapidly evolving technology demands a highly knowledgeable workforce and a civic culture of involvement and creativity. The $21^{\text {st }}$ Century presents major challenges and increased opportunities for University scholarship. We need to address the need for disseminating and applying state-of-the-art knowledge throughout society. We need to promote integration across disciplines and between the university and the field. Applications of knowledge to real-world issues need to be addressed in a rapid-response mode. Creativity and flexibility are required in responding to the public's need for lifelong learning.

University and college administrators and faculties are responding by rethinking what constitutes high 
quality scholarship. Penn State has been seriously engaged in this discussion for several years as evidenced by the work of the University Faculty Senate and its Committee on Outreach, by the restructuring of outreach as a University-wide office under the Vice President for Outreach and Cooperative Extension, and by the creation of the Coordinating Council for Outreach and Cooperative Extension. Notable also is the key role Penn State President Graham Spanier has played as chair of the Kellogg Commission on the Future of State and Land-Grant Universities that published Returning to Our Roots: The Engaged Institution. Other visible indicators include the University's creation of the World Campus to expand outreach on a global basis and University-wide initiatives on Children, Youth and the Family, Information Science and Technology, and the Making Life Better initiative for "promoting human, economic, and cultural development through the integrated missions of teaching, research, and service."

Outreach has been a critical component of Penn State's mission since its inception. It holds a longstanding and impressive record of excellence in this regard. The 1998 Penn State Outreach Inventory lists outreach initiatives offered in the 67 counties of Pennsylvania. Participants come from all 50 states and 80 countries. More than 1,500 faculty and instructors from all Penn State locations and every academic college in the University provide outreach programs. These efforts give Penn State the largest unified outreach effort in American higher education. But if Penn State is to continue to be a leader in outreach in the $21^{\text {st }}$ Century, it needs to address some major challenges and opportunities in outreach.

One major challenge to outreach programs is the current thinking about what constitutes high quality University scholarship. The current promotion and tenure evaluation process is dominated by an academic culture that shows preference towards rewarding basic research and resident education over all other forms of scholarship. Outreach scholarship suffers because it has been judged a secondary activity or has been considered too difficult to assess. We believe that many faculty and administrators need to gain an appreciation of outreach scholarship and how it can be effectively integrated into the promotion and tenure process.

As a result, faculty who perform outreach may not receive equitable recognition and reward. A brief perusal of the Outreach Inventory suggests that many tenure-track faculty are not involved in outreach as we move into the $21^{\text {st }}$ Century. If the University is to continue to lead the way in outreach, faculty and administrators need to have a creative understanding of outreach scholarship and how it can be effectively integrated into the promotion and tenure process. Scholarship must be redefined more broadly to adequately address the needs of the public, and criteria and methods of evaluation must be redefined to recognize and reward all forms of scholarship equitably.

A learning community was created as part of the KEYSTONE 21 Project to consider the meaning of scholarship in the contemporary university and to consider the role of outreach therein. The KEYSTONE 21 Project is a partnership among the Pennsylvania State University College of Agricultural Sciences, The Pennsylvania State University Commonwealth Educational System, Cheyney University of Pennsylvania and the Rodale Institute Experimental Farm. KeYstone 21, funded by the W.K. Kellogg Foundation, was one of 14 university-based projects that collectively form the Food Systems Professions Education Initiative. With the Food Systems Professions Education initiative, the W.K. Kellogg Foundation offered universities the opportunity to design and implement new food systems education programs for the $21^{\text {st }}$ century. This process involves long-term planning, innovative approaches to problem solving, and new collaborations among higher education, communities, voluntary organizations, government, and business. 
KEYSTONE 21 pursued two objectives: first, to prepare food systems professionals for the $21^{\text {st }}$ century through the development of new forms of teaching, research, and service that demonstrate our commitment to all residents of the Commonwealth. The second goal of the project was broader in scope and focused on strengthening the ability of land-grant universities to meet the challenges posed by rapid social change. If land-grant universities are to remain socially relevant, they must address the public's changing needs, values, and priorities. Faculty and staff need to be encouraged and rewarded for developing programs and projects that address society's concerns and issues. A key issue in this process is a land-grant university's ability to recognize and reward the full range of scholarship being conducted by its faculty and staff.

In the spring of 1998, the KEYSTONE 21 Advisory Committee met to discuss how it could promote leadership for innovation and change in the University. We were looking for ways to create new definitions of scholarship for the $21^{\text {st }}$ Century. New definitions of scholarship would value outreach and reward socially relevant forms of research, teaching and service. We discussed and reviewed the current University reward system. We acknowledged the existence of University policies developed by the University Faculty Senate and administration for recognizing outreach in the three mission areas of teaching, research, and service. But we also noted that problems existed for implementing the policies within colleges and departments, where promotion and tenure decisions are made. Specifically, we noted that outreach teaching scholarship and outreach research scholarship have not been receiving fair and equitable evaluation in comparison to basic research scholarship. Nor is the current policy addressing the issue of service scholarship in a complete and equitable manner.

Although University policy formally recognizes these critical components of the land-grant mission, the evaluation process is dominated by an academic culture that primarily recognizes non-outreach and nonservice activities. And we are concerned about the implications of this policy, particularly, how it could adversely affect the University's land grant mission. We understand that these concepts are not easily understood and that discrepancies in interpretation and implementation exist between colleges. And we realize that this poses a serious challenge to the three areas of the University's land grant mission: teaching, research, and service. Such a challenge demands to be pursued with a novel approach. After considerable reflection and deliberation, we decided it was necessary to broaden this discussion. Our goal was to create a "learning community" to explore the criteria and methods for a land-grant institution to evaluate scholarship and outreach activities in the $21^{\text {st }}$ Century.

A learning community is a group of people who agree to engage in an open conversation of discovery about a topic of mutual interest. Its members enter into the relationship with an assumption of competence on the part of each and trust in all. The conversation is characterized by curiosity in exploring new ideas, openness to all perspectives and points of view and a commitment to working toward a collaborative result. As noted by Charles Hardy (1995) at the London Business School, "Lonely learners are often slow and poor learners, whereas people who collaborate learn from each other and create synergy" [1]. Such communities are held together not by authority or influence but by a commitment to a common goal and a promise to continue the conversation.

Learning organizations are a space for generative conversations and concerted action. In them, language functions as a device for connection, invention and coordination. People can talk from their hearts and connect with one another in the spirit of dialogue (from the Greek dia + logosmoving through). Their dialogue weaves a common ongoing fabric and connects them at a deep level of being. When people talk and listen to each other this way, they create a field of alignment that produces tremendous power to invent new realities in conversation and to bring about these new realities in action. [2] 


\section{THE PROCESS}

With this understanding of learning organizations, a five-phase process was created:

\section{Phase 1: Initiation}

As a first step, we established a broad-based learning community among a small but dedicated group of Penn State faculty and administrators. Potential members were identified by nominations of the Keystone 21 Advisory Committee, the Vice-Provost and the Vice President for Outreach, Director of Cooperative Extension and Associate Dean, College of Agricultural Sciences. At an organizational meeting, the purpose and challenge of the learning community was introduced. Nominees were invited to engage in a 6-12-month deliberative dialogue, to indicate their commitment to the learning community and to refining the topic. The meeting concluded with all nominees agreeing to become members. Learning community members [3] made a commitment to attend all of the meetings, to complete assigned tasks between meetings, and to come to the meetings prepared to participate in deliberating the issues.

The ground rules for the learning community were established as follows

- All participants would have equal status regardless of University position.

- The format and agenda of each meeting would be flexible - the direction could change as the dialogue proceeded.

- All ideas would be valued.

- The goal would be to create a common understanding on the meaning of outreach scholarship in teaching, research, and service.

\section{B. Phase 2: Establishment}

The learning community chose UniSCOPE, University Scholarship and Criteria for Outreach and Performance Evaluation, as a title to encapsulate its chosen mission. Its task would be to explore the criteria and methods for a land-grant university to evaluate scholarship and outreach activities in the 21st century. As a learning community, UniSCOPE would be open to redefinition and change as the process unfolded. Initial discussions addressed the following questions: What is scholarship in a land-grant university setting? And what is outreach in this context? Later deliberations addressed issues of design and implementation of processes for documenting and evaluating all forms of University scholarship. 
Figure 1. UniSCOPE focus on scholarship

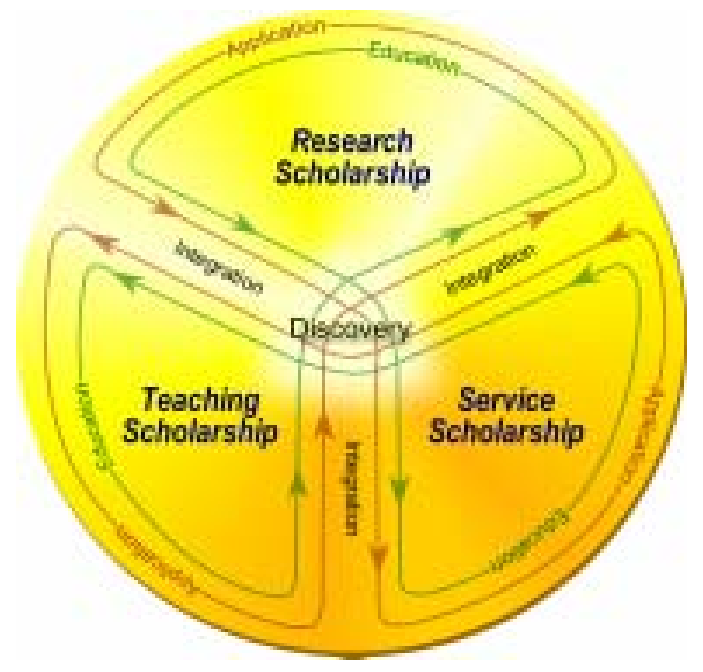

\section{Phase 3: Implementation}

The learning community process of discovery and deliberation to date has addressed the following topics:

- March 24, 1998: Organizational Meeting: Theodore R. Alter, KeYstone 21 Project Director

- April 13, 1998: Penn State's Definition of Scholarship - Dr. John Brighton, Provost. Learning Community Members Definitions of Scholarship - Dr. Drew Hyman and Dr. Susie Whittington

- May 14, 1998: Reward and Recognition Structure for Faculty Outreach Activities - Jacob DeRooy, Chairman of Faculty Senate Committee on Outreach

- June 11, 1998: What We've Learned and Where Are We Going as a Learning Community?

- July 14, 1998: The Scholarship of Teaching - Jeremy Cohen, Interim Dean, College of Communications

- September 30, 1998: Penn State's Definition of Outreach and Service Scholarship - James Ryan, Vice President for Outreach and Cooperative Extension.

- October 22, 1998: Discussion of Progress to Date and Next Steps

- November 24, 1998: Tussey Mountain Retreat; Discussion of final product possibilities.

- December 22, 1998: David Roth, Senate Committee on Outreach, joins the learning community as liaison. Consideration of Wisconsin and Michigan State outreach evaluation documents. Outline for a UniSCOPE position paper.

Meetings from January 28, 1999 through May 23, 2000 discussed and refined the development of the UniSCOPE models of scholarship and the draft of UniSCOPE 2000: A Multidimensional Model for Scholarship in the 21st Century.

\section{Phase 4: Creating a Model of Scholarship}

The UniSCOPE learning community formulated a model of University scholarship grounded in three main missions of the University: teaching, research, and service. The Advisory Committee provided information and engaged the learning community in considering the purposes of outreach and outreach scholarship in each of the three main missions of the University. Documents from other Big Ten universities (Wisconsin, Michigan State, and Illinois), and Oregon State and Portland State were consulted. They were valuable materials for developing the UniSCOPE model which we expect to unfold and evolve as the dialogue continues. 


\section{E. Phase 5: Products}

Suggestions for final products of the UniSCOPE project include the following possibilities:

- A policy paper on scholarship and its meaning for teaching, research, and service in the $21^{\text {st }}$ century land-grant institution.

- Development of a format and materials for a deliberative dialogue to be used in University colleges and departments toward implementing the results of the UniSCOPE learning community and developing unit-specific criteria for evaluating teaching, research, and service scholarship.

- Initiation of a University-wide learning community process for both implementing the recommendations of the UniSCOPE learning community and developing unit-specific criteria for evaluating teaching, research, and service outreach.

- A University-wide conference or series of workshops to discuss and implement the results of the UniSCOPE process.

- An "Internet Forum" open to all faculty to present the UniSCOPE model(s) and engage the University community in a deliberative dialogue about scholarship and its meaning at Penn State. The result would be a refinement of the model(s) and suggestions for applications in the University

- Other (as emerges from the process).

\section{CONCLUSION}

UniSCOPE is thus one of the many activities of the University that is addressing issues of appropriate recognition of outreach and other forms of scholarship. The University Faculty Senate Committee on Outreach and the Office of the Vice President for Outreach and Cooperative Extension are the respective units representing Penn State faculty and the administration with interest in this issue. UniSCOPE seeks to contribute to the emergence of an academic culture that equitably recognizes, respects, and rewards all dimensions of scholarship as we begin the $21^{\text {st }}$ century.

For copies of the UniSCOPE 2000: A Multidimensional Model for Scholarship in the 21st Century contact Dr. Elise Gurgevich at EliseG@psu.edu or (814) 863-1787.

\section{REFERENCES}

1. Handy C. Managing the Dream. In: Chawla, S. and Renesch, J. (Eds.), Learning Organizations, Portland, OR: Productivity Press, 1995.

2. Kofman, F. and Senge, P. Communities of Commitment. In: Chawla, S. and Renesch, J. (Eds.), Learning Organizations, Portland, OR: Productivity Press, 1995.

3. Learning Community members include John E. Ayers, Professor of Plant Pathology; Erskine H. Cash, Professor of Animal Science; Donald E. Fahnline, Associate Professor of Physics; David P. Gold, Professor Emeritus of Geology; Elise A. Gurgevich, KEYSTONE 21 Project Coordinator; Robert O. Herrmann, Professor Emeritus of Agricultural Economics; Drew Hyman, Professor of Public Policy and Community Systems; Peter C. Jurs, Professor of Chemistry; David E. Roth, Associate Professor of Engineering; John D. Swisher, Professor of Counselor Ed./Psychology/Rehab Ed.; M. Susie Whittington, Associate Professor of Agricultural and Extension Education; Helen S. Wright, Professor of Nutrition. 


\section{ABOUT THE AUTHORS}

Elise Gurgevich is the project coordinator for KEYSTONE 21, a project under the W.K. Kellogg Foundation national Food System Professions Education initiative. She is a member of the UniSCOPE learning Community. She earned a M.P.H. from the University of Michigan and a Ph.D. from The Pennsylvania State University.

Drew Hyman is a Professor in the Department of Agricultural Economics and Rural Sociology at Penn State. His work focuses on community and economic development, citizen participation, deliberative democracy, consumer education and complaint-handling, and computer-based information systems. He is the Chair of the UniSCOPE Learning Community.

Theodore R. Alter is associate vice president for outreach and director of Cooperative Extension at The Pennsylvania State University. He is also an associate dean in the College of Agricultural Sciences. Previously, Alter was agricultural economics and rural sociology department head and interim dean of the College of Agricultural Sciences. 